\title{
The Laryngeal Mask Airway in Pediatric Anesthesia
}

\author{
Wen Xian Li* and Shuang shuang LI \\ Department of Anesthesiology, Eye \& ENT Hospital of Fudan University, China
}

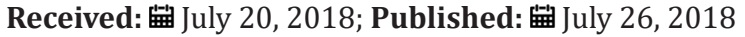

*Corresponding author: Wen-Xian Li, Department of Anesthesiology, Eye \& ENT Hospital of Fudan University, 83 Fenyang Road, Shanghai 200031, China.

Abbreviations: LMA-Laryngeal Airway Mask; SV-Spontaneous Ventilation; PSV- Pressure Support Ventilation; PCV-Pressure-Controlled Ventilation

\section{Introduction}

Since the reports that the laryngeal airway mask (LMA) could be used safely and effectively in pediatric anaesthesia in 1990s [1,2], LMA are currently recommended for use in a variety of challenging scenarios, such as in the difficult airway, remote locations, ventilation during resuscitation, long-duration surgeries, in children with recent upper respiratory infection, even in laparoscopic surgery and prone position procedures. In the past years, there are many randomized trials carried out in pediatric group among various clinical scenarios. This mini-review aims to present the current literatures on the usage of the laryngeal airway mask in children.

\section{Size of the Laryngeal Mask Airway}

The successful use of the laryngeal mask airway in children depends partly on the correct selection of size [3]. The appropriate size of the laryngeal mask airway in children is usually determined by the pediatric's body weight. In addition, there are several alternative methods to predict the size of the laryngeal mask airway. Gallart L et al. [4] proposed a new method that the size of the laryngeal mask airway was determined by the combined widths of the patient's index, middle and ring fingers. They compared the results with the standard method recommended by the manufacturer's weight-related guidelines and found an "excellent agreement" between both methods. The literature proposed that this new approach is of valid and practical use in children. Zahoor A et al. [5] chose the size of the laryngeal mask airway in children according to the size of the external ear that was associated with a success rate of $93 \%$.

That simple method might allow a rapid choice of the correct size of laryngeal mask airway and eliminate the need to remember different tables or formulae. However, in over- or underweight children, Kim $\mathrm{HJ}$ et al. [6] found that laryngeal mask airway size according to the manufacturer's weight-based recommendation is to be preferred in overweight children, but laryngeal mask airway size by an ideal weight estimated from the pediatric patient's age is a better choice in underweight children.

\section{Insertion Techniques}

A relatively large tongue, a higher and more anterior larynx with a relatively large floppy epiglottis and frequent presence of tonsillar hypertrophy may make correct placement of LMA more difficult in pediatric patients. Hence, the insertion of the LMA by the standard technique is not always easy. Alternative techniques such as rotational, cuff partially inflated and lateral approaches have been used to improve the ease and success of LMA [7] insertion in children. Ghai B et al. [8] compared the success and ease of insertion of three techniques of laryngeal mask airway: the standard Brain technique, a lateral technique with cuff partially inflated and a rotational technique with cuff partially inflated. A rotational technique with partially inflated cuff is associated with the highest success rate of insertion and lowest incidence of complications and could be the technique of first choice for LMA insertion in pediatric patients.

\section{Ventilation Modalities}

In clinical situations, there may be different strategies for ventilating children during surgical procedures. Templeton TW et al. $[9,10]$ compared 3 different ventilation modalities (spontaneous ventilation (SV), pressure support ventilation (PSV), and pressurecontrolled ventilation (PCV)) in pediatric patients with a ProSeal laryngeal mask airway. They found that all 3 modes of ventilation using a PLMA were safely used, PSV and PCV were more appropriate ventilation strategies to more optimally control ETCO2 over time.

\section{Removal of the Laryngeal Mask Airway}

Anesthesiologists have been debating on when and how to remove the laryngeal mask airway in children for a long time. Kitching AJ et al. [11] advocated that removal of the laryngeal mask airway during deep anaesthesia reduced coughing in the immediate postoperative period for older infants and young children. ThomasKattappurathu G et al. [12] suggested that lateral positioning of children for removal of the LMA provided the safest conditions if the LMA is to be removed at a deep plane of anaesthesia for children more than 1 year old. 


\section{Compare with Endotracheal Tube}

The laryngeal mask airway and endotracheal tube are the classic tools to management the airway of children receiving general anesthesia. The endotracheal tube carries more risk of trauma to the airway while the laryngeal mask airway is criticized because it cannot wholely protect against aspiration. Patki A [13] compared LMA with endotracheal tube in pediatric airway management. The literature indicated that the LMA was seen to have three advantages over the tracheal tube: lower incidence of cough during emergence, lower postoperative sore throat and lower postoperative vomiting. The LMA provides lesser perioperative airway complications, in comparison to the conventional tracheal tube. In infants (aged 0-12 months) undergoing minor elective procedures [14], greater rates of overall PRAE were found in endotracheal tube group than LMAs group. The risk of PRAE was tripled in endotracheal tube group. Laryngospasm and bronchospasm (major PRAE) occurred approximately five times in endotracheal tube group. However, comparisons among different LMA types, different patient's conditions and different surgical procedures might be explored.

\section{Conclusion}

Overall, the availability of smaller sizes of laryngeal mask airway has brought a significant change in the whole approach to airway management in children. The results of several surveys among pediatric anesthetists indicates that the laryngeal airway mask is frequently the airway device of choice in routine practice and difficult airways in children $[15,16,17]$. However, the risk of pulmonary aspiration, lingual edema, and nerve damage caused by the laryngeal airway mask must be concerned. Further research may bring in more insight into the safely usage of the laryngeal airway mask.

\section{References}

1. Mason DG, Bingham RM (1990) The laryngeal mask airway in children. Anaesthesia 45(9): 760-763.

2. Johnston DF, Wrigley SR, Robb PJ, Jones HE (1990) The laryngeal mask airway in pediatric Anaesthesia. Anaesthesia 45(11): 924-927.

3. Brimacombe J, Brain AIJ, Berry A (1997) Nonanesthetic uses. In: The laryngeal mask airway: a review and practice guide. Philadelphia, Pennsylvania: Saunders pp. 216-277.

4. Gallart L, Mases A, Martinez J, Montes A, Fernandez Galinski S, et al.
(2003) Simple method to determine the size of the laryngeal mask airway in children. Eur J Anaesthesiol 20(7): 570-574.

5. Zahoor A, Ahmad N, Sereche G, Riad W (2012) A novel method for laryngeal mask airway size selection in paediatric patients. Eur J Anaesthesiol 29(8): 386-390.

6. Kim HJ, Park MJ, Kim JT, Kim CS, Kim SD, et al. (2010) Appropriate laryngeal mask airway size for overweight and underweight children. Anaesthesia 65(1): 50-53.

7. Nakayama S, Osaka Y, Yamashita M (2002) The rotational technique with a partially inflated laryngeal mask airway improves the ease of insertion in children. Paediatr Anaesth 12(5): 416-419.

8. Ghai B, Makkar JK, Bhardwaj N, Wig J (2008) Laryngeal mask airway insertion in children: comparison between rotational, lateral and standardtechnique. Paediatr Anaesth 18(4): 308-312.

9. Templeton TW, Hoke LK, Yaung J, Aschenbrenner CA, Rose DM, et al. (2016) Comparing 3 ventilation modalities by measuring several respiratory parameters using the ProSeal laryngeal mask airway in children. J Clin Anesth 34: 272-278.

10. Templeton TW, Hoke LK, Templeton LB, Ririe DG, Rose DM, et al. (2016) A comparison of 3 ventilation strategies in children younger than 1 year using a ProSeal laryngeal mask airway: a randomized controlled trial. J Clin Anesth 35: 502-508.

11. Kitching AJ, Walpole AR, Blogg CE (1996) Removal of the laryngeal mask airway in children: anaesthetized compared with awake. $\mathrm{Br} J$ Anaesth 76(6): 874-876.

12. Thomas Kattappurathu G, Kasisomayajula A, Short J (2015) Best position and depth of anaesthesia for laryngeal mask airway removal in children: A randomised controlled trial. Eur J Anaesthesiol 32(9): 624-630.

13. Patki A (2011) Laryngeal mask airway vs the endotracheal tube in paediatric airway management: A meta-analysis of prospective randomised controlled trials. Indian J Anaesth 55(5): 537-541.

14. Drake-Brockman TF, Ramgolam A, Zhang G, Hall GL, von UngernSternberg BS (2017) The effect of endotracheal tubes versus laryngeal mask airways on perioperative respiratoryadverse events in infants: a randomised controlled trial. Lancet 389(10070): 701-708.

15. Bradley AE, White MC, Engelhardt T, Bayley G, Beringer RM (2013) Current UK practice of pediatric supraglottic airway devices - a survey of members of the Association of Paediatric Anaesthetists of Great Britain and Ireland. Paediatr Anaesth 23(11): 1006-1009.

16. Patel A, Clark SR, Schiffmiller M, Schoenberg C, Tewfik G (2015) A survey of practice patterns in the use of laryngeal mask by pediatric anesthesiologists. Paediatr Anaesth 25(11): 1127-1131.

17. Kaniyil S, Smithamol PB, Joseph E, Krishnadas A, Ramadas KT (2017) A Survey of Current Practice of Supraglottic Airway Devices in Pediatric Anesthesia from India. Anesth Essays Res 11(3): 578-582.
ISSN: 2574-1241

DOI: $10.26717 / B J S T R .2018 .07 .001480$

Wen Xian Li. Biomed J Sci \& Tech Res

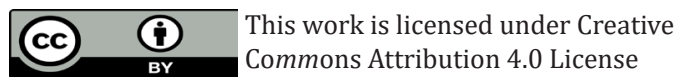

Submission Link: https://biomedres.us/submit-manuscript.php

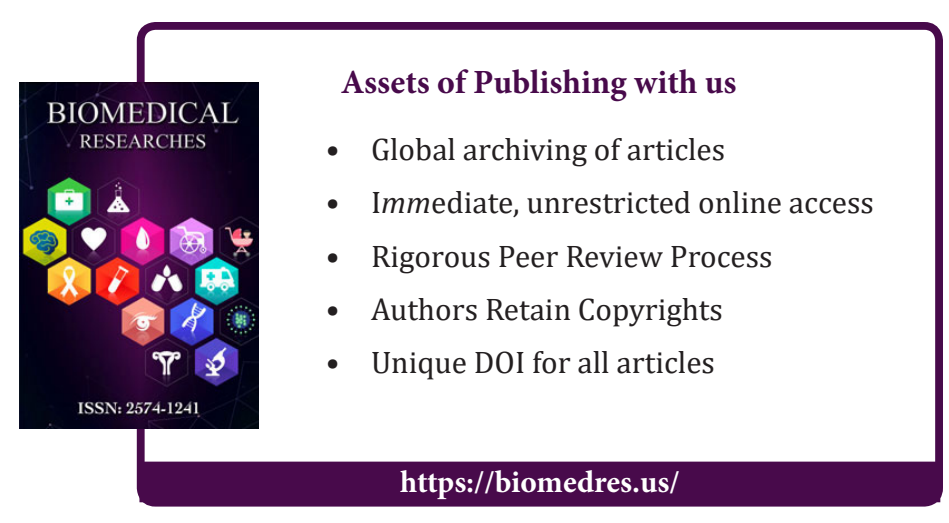

